\title{
Rhythm of tantrums
}

\author{
Sravanti $\mathbf{L}^{1}$, Karki $\mathbf{U}^{1}$, Seshadri $\mathbf{S}^{2}$
}

1. Senior Resident, Department of Child and Adolescent Psychiatry, NIMHANS, Bengaluru, India 2.Prof and Head, Department of Child and Adolescent Psychiatry, NIMHANS, Bengaluru, India

\section{E-mail *Corresponding author : karkiutkarsh@gmail.com}

\begin{abstract}
Temper tantrums are part of the normal course of development occurring most commonly in toddlers. There is a chance that these tantrums can become pathological, more so in case of dysfunctional family dynamics. And as it happens in the context of family, it can become a "family problem" as well. Early identification of abnormal tantrum behaviour and interventions directed to help parents handle these tantrums can prevent their long-term adverse consequences. The focus of this article is on why temper tantrums occur, what elements constitute a tantrum, stages through which they progress and simple methods of handling tantrums. It is done with the help of an example and some illustrations that can be useful in psychoeducation to families about tantrum behaviour.
\end{abstract}

Keywords: Temper tantrums, anger outbursts, tantrum behaviour management

\section{INTRODUCTION}

Have you ever noticed a child rolling on floor and whining and wondered what exactly goes on in the child's mind while doing so? Well, temper tantrums are universal and are distressing to the parents all over the world. They are part of the normal course of development occurring most commonly in toddlers. ${ }^{1}$ Improper parenting practices play a role in accentuating these tantrums beyond the range of what falls under normal development leading to behavioural problems of childhood. Early identification of what constitutes an abnormal tantrum behaviour and interventions directed to help parents handle these tantrums can prevent their long-term adverse consequences.

Generally tantrums exhibited by $1.5-5$ year olds on an average occur once a day lasting for less than five minutes. ${ }^{2}$ Tantrums can serve as a marker of underlying psychiatric disorder. ${ }^{3}$ Needlman et al reported that $52 \%$ of children exhibiting severe tantrums had other nontantrum-related behavioral/emotional problems. ${ }^{4}$ Bhatia et al studied 800 children aged between 3 to 12 years attending a pediatric department and concluded that they are most common in children aged 3-5 years and the prevalence decreases with age. Parental overprotection, negligence and discord were found to be associated with tantrum behaviour. Children were found to have associated behavioural problems such as hyperactivity, thumb-sucking, bed-wetting and sleep disturbances. ${ }^{5}$

The focus of this article is on why temper tantrums occur, what elements constitute a tantrum, stages through which they progress and simple methods of handling tantrums.

\section{TEMPER TANTRUM}

Temper tantrums occur because toddlers cannot regulate their anger that arises when they are prevented from exercising autonomy. While 
they are more common in a determined child with abundant energy, ${ }^{1}$ they can also occur when a child is hungry or fatigued, ${ }^{6}$ bored or ill. ${ }^{1}$ Children modify emotional expressions to serve personal needs and exaggerate true feelings of anger and distress to get attention. ${ }^{7}$ Parental responses and family environment play a role in helping the child develop adequate selfregulatory capacities. Various parenting practices that accentuate and perpetuate tantrums include inconsistency, excessive strictness, use of corporal punishment, ${ }^{4}$ unreasonable expectations, overprotection and overindulgence. ${ }^{1}$ Mother being the exclusive caregiver, maternal depression and irritability, low education and marital stress are some psychosocial factors that have been identified to be associated with tantrums. ${ }^{4}$

Young children find it difficult to regulate their emotions. Self-regulation is the ability to modulate attention, affect and behaviour to suit a given context. ${ }^{8}$ Effortful control is one of the important dimensions of temperament and emotional self-regulation requires effortful control of emotions. It improves gradually during development as a result of the maturation of prefrontal cortex and assistance of caregivers during stressful situations. Executive functions such as attention focusing, attention shifting, inhibiting negative emotions and behaviours and planning help in exercising selfregulation. ${ }^{9}$

\section{Components of a tantrum}

Tantrum is an expression of two overlapping emotional and behavioural processes. Its chief components are anger and distress. Anger rises quickly and peaks at or near the beginning of the tantrum. Whining, crying and comfortseeking that are the sub-components of distress slowly increase in probability across the tantrum. ${ }^{2}$ Coping style is another component of a tantrum. Eg: a child may "drop down" or "run away". It reflects the tendency to submit to authority or escape from the situation. ${ }^{10}$

\section{Stages of a tantrum}

Research has shown that a typical tantrum progresses and resolves over three stages viz. the screaming and yelling, physical actions and crying and whining. ${ }^{11}$ The three stages have been illustrated using an example of a young child demanding to ride on a giant wheel.

Stage 1: Child shouts and yells demanding his parents to let him ride on the giant wheel in an amusement park (Fig. 1). Parents think it is an unreasonable demand as he is much younger than the age limit that is specified for going on it. They try to explain it to him, but he doesn't listen.

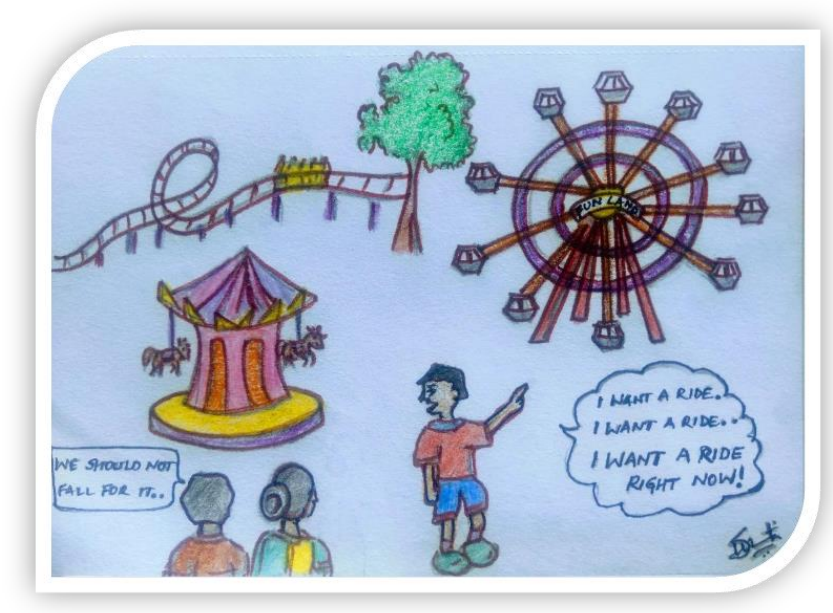

Figure 1: Screaming \& Yelling

Stage 2: Child falls on the ground and continues to scream (Fig 2). A study done by Potegal et al concluded that if a child stamped or fell to the floor within 30 seconds of the tantrum, it was likely to be shorter and likelihood of subsequent parental intervention was also less. ${ }^{2}$

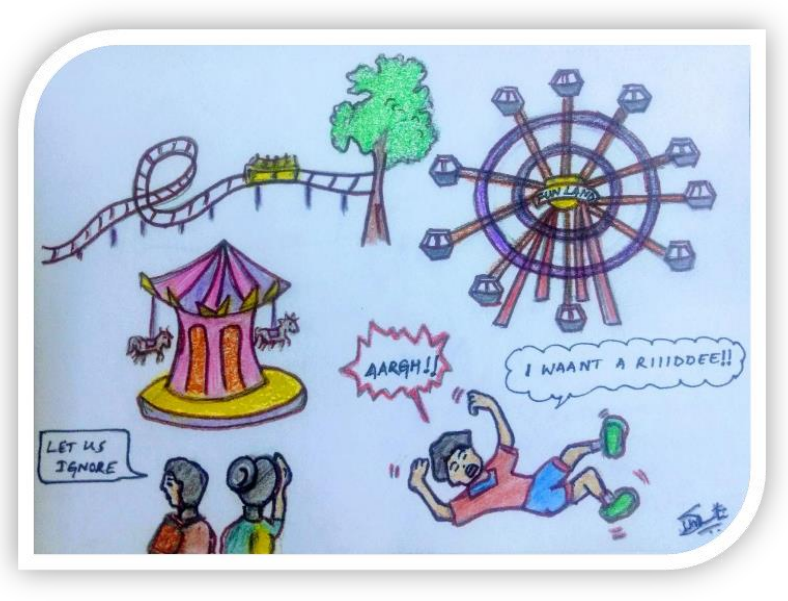

Figure 2: Physical actions 
Stage 3: Child whines (Fig 3). By now, child has expelled a lot of energy and is now fussing about his demand not being met. Comforting the child at this point, helps him feel better.

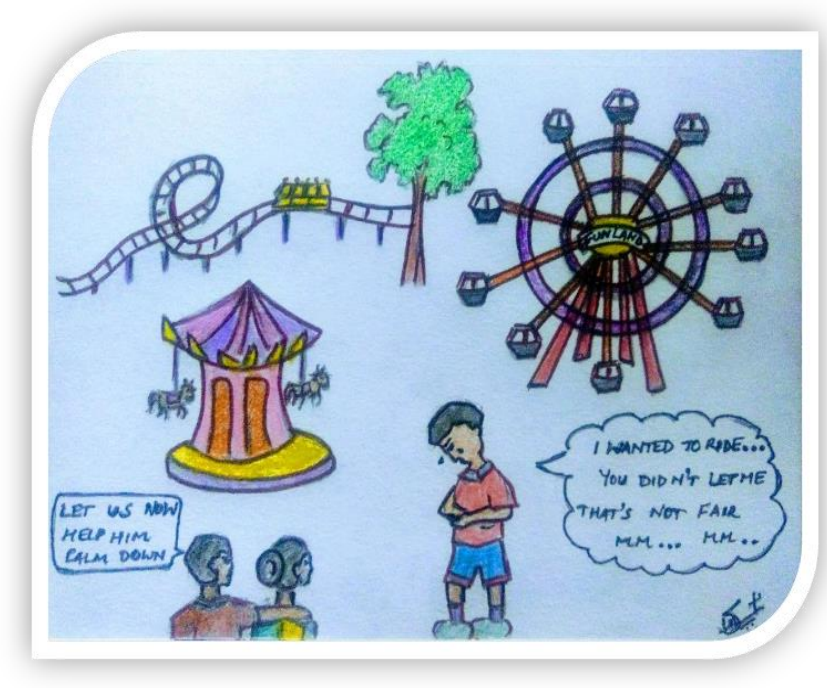

Figure 3: Crying \& whining

\section{Normal v/s Abnormal tantrum behaviour}

Temper tantrums are normative during toddlerhood and even in pre-schoolers generally arising with the child's resistance to comply and frustration with external events. They typically appear between one and three years of age, when a child's language skills to describe his/her emotions and desires is still limited. As the child develops emotional vocabulary, selfregulation skills and emotional display rules they reduce significantly especially by the age of four - five years. During this period physical aggression reduces, however verbal and instrumental aggression begin to increase. ${ }^{12}$ While aggression of most two-year olds is reactive in nature, it becomes more instrument or goal-oriented and calculated between the ages of three and four years. ${ }^{7}$ By about five to six years of age, tantrum behaviours decrease significantly as children also become good at problem solving especially when exposed to appropriate modelling by adults and peers. ${ }^{12}$ In clinical practice, often children present with outbursts of anger and agitation that are so severe that they pose danger to child and others..$^{13}$ These outbursts seem irrational and the triggers could be trivial. ${ }^{14}$ They are sometimes called "rages" and have been seen to occur in association with conditions such as mania, 15 intermittent explosive disorder conduct disorder, ${ }^{16}$ Tourette's disorder, autism and other developmental disabilities. ${ }^{17}$

Also termed angry agitated outbursts these could be the exaggerated versions of ordinary childhood tantrums. They may contain behaviours with a range of anger intensities and may show a characteristic pattern of rise and fall over time. They have a relatively steady-state distress component.

Both internalizing and externalizing disorders can present with excessive tantrums. ${ }^{18}$ Research shows that anxiety about a perceived threat may trigger a tantrum to avoid that situation. ${ }^{19}$ Thus, intense anxiety might not only trigger tantrums, but can also intensify distress.

\section{PRINCIPLES UNDERLYING MANAGEMENT OF TEMPER TANTRUMS}

Disregard and ignore are a couple of strategies that can be adopted by parents to handle temper tantrums. To "disregard" is to ignore the tantrum behaviour but not the child. Comforting and soothing the child but not giving in to the demand is a preferable approach. However, if it does not work or is not feasible "ignoring" helps in tackling the meltdown. But parents need to nurture the child after the tantrum has subsided, helping the child to learn to express negative emotions in acceptable ways. ${ }^{1}$ Differentially reinforcing appropriate behaviours, identifying triggers and intervening early on can prevent tantrum-behaviours.

In the previous example, since trying to explain to the child did not work, parents chose to ignore the tantrum. While doing so, they have ensured child's physical safety. They then identify when he has calmed down a bit and approach him (Fig 4). They try to soothe him, explain to him again and offer an alternative ride. 


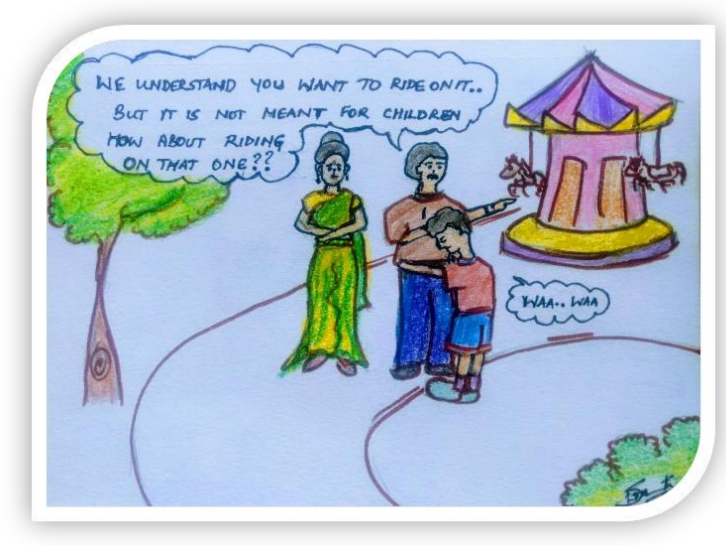

Figure 4

Child is more amenable now and settles for a different option suggested to him by his parents (Fig 5). Distracting the child by guiding him to adopt acceptable alternatives to the prohibited behaviour or suggesting better ways to handle his distress can be other methods of handling such a situation. ${ }^{20}$

However, in this case parents' negotiation skills have worked. The timing of approaching the child determines its success.

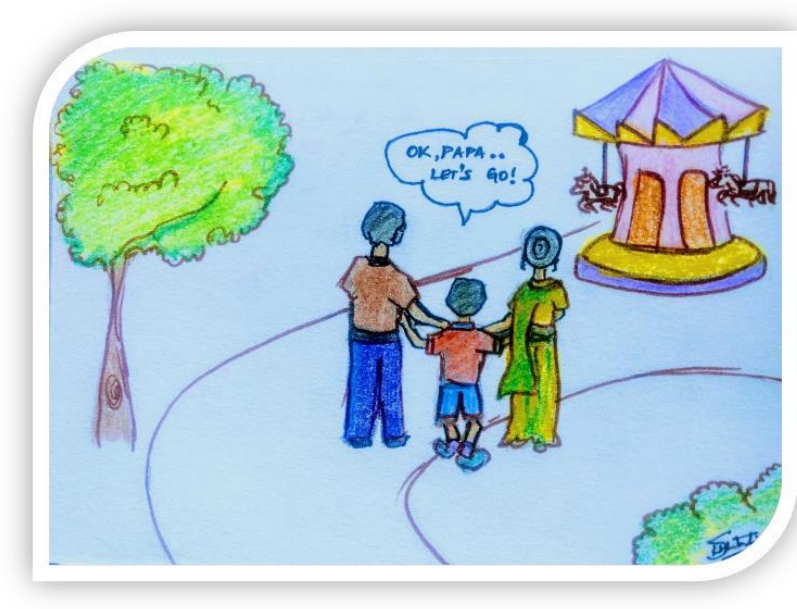

Figure 5

Psychoeducating the parents about tantrum behaviours by doing a functional analysis and helping them identify parental behaviours that are encouraging and maintaining tantrums is helpful. Parents must be sympathetic but setting clear and defined limits by not giving in to tantrums is equally important. Individual work with the child can also be done with a focus on anger-management techniques and social skills training. ${ }^{20}$

\section{CONCLUSION:}

Temper tantrums are a normal feature in toddlers and pre-schoolers that occur due to poor regulatory capacities to inhibit negative emotions. Later children learn to restrain emotional expressions, understand emotional display rules and substitute their behaviours with more socially acceptable forms. It is important to identify when a tantrum is not ageappropriate or is an indicator of an underlying emotional disturbance and intervene early to prevent major psychiatric disorders.

\section{REFERENCES:}

1. Leung AK, Fagan JE. Temper tantrums. Am Fam Physician 1991;44(2):559-63

2. Potegal M, Kosorok MR, Davidson RJ. Temper tantrums in young children: 2. Tantrum duration and temporal organization. I Dev Behav Pediatr 2003;24(3):148-54

3. Belden AC, Thomson NR, Luby JL. Temper Tantrums in Healthy Versus Depressed and Disruptive Preschoolers: Defining Tantrum Behaviors Associated with Clinical Problems. J Pediatr 2008;152(1):117-122. doi:10.1016/j.jpeds.2007.06.030.

4. Needlman R, Stevenson J, Zuckerman B. Psychosocial correlates of severe temper tantrums. I Dev Behav Pediatr 1991;12(2):77-83.

5. Bhatia MS, Dhar NK, Singhal PK, Nigam VR, Malik SC, Mullick DN. Temper tantrums. Prevalence and etiology in a non-referral outpatient setting. Clin Pediatr (Phila) 1990;29(6):311-5.

6. Mascolo MF, Fisher KW. The codevelopment of self and sociomoral emotions during the toddler years. In: Brownell CA \& Kopp CB (Eds.), Socioemotional development in the toddler years: transitions and transformations. New York: Guilford; 2007. p. 66-99.

7. Berk LE. Emotional Development, In: Child Development. 9th ed. Noida: Pearson India Education Services; 2017. p. 409-13.

8. Posne MI, Rothbart MK. Developing mechanisms of self-regulation. Dev Psychopathol 2000;12(3):427-41.

9. Eisenberg N, Spinrad TL. Emotion-related regulation: Sharpening the definition. Child Dev 2004;75:334-9

10. Potegal M, Davidson RJ. Temper tantrums in young children: 1. Behavioral composition. I Dev Behav Pediatr 2003;24(3):140-7.

11. Vedantam S. NPR Choice page [online] Npr.org. What's behind a temper tantrum? Scientists deconstruct the screams. Available at: https://www.npr.org/sections/healthshots/2011/12/05/143062378/whats-behind-a-tempertantrum-scientists-deconstruct-the-screams [Last updated on 2011 Dec 5; Last accessed on 2018 Jul 11] 
12. Guerra NG, Williamson AA, Lucas-Molina B. Normal development: infancy, childhood and adolescence. In: Rey JM (editor), IACAPAP e-Textbook of Child and Adolescent Mental Health. Geneva: International Association for Child and Adolescent Psychiatry and Allied Professions; 2015.

13. Bambauer KZ, Connor DF. Characteristics of aggression in clinically referred children. CNS Spectrum 2005;10:709-718.

14. Ryan EP, Hart VS, Messick DL, Aaron J, Burnette M. A prospective study of assault against staff by youths in a state psychiatric hospital. Psychiatric Service 2004;55:665-670.

15. Leibenluft E, Charney DS, Towbin KE, Bhangoo RK, Pine DS. Defining clinical phenotypes of juvenile mania. Amer J Psychiatry 2003;160:430-437. [PubMed: 12611821]

16. Campbell M, Gonzalez NM, Silva RR. The pharmacologic treatment of conduct disorders and rage outbursts. Psychiatr Clin North Amer 1992;15:69-85. [PubMed: 1549549]

17. Sukhodolsky DG, Cardona L, Martin A. Characterizing aggressive and noncompliant behaviors in a children's psychiatric inpatient setting. Child Psychiatry Hum Dev 2005;36:177-193. [PubMed: 16228146]

18. Potegal M. Tantrums in externalizing, internalizing and typically developing 4 year olds; Poster presented at the meeting of the Society for Research on Child Development; Atlanta, GA:2005. Apr

19. Varley CK, Smith CJ. Anxiety disorders in the child and teen. Pediatr Clin North Am 2003;50(5):1107-38.

20. Lecuyer E, Houck GM. Maternal limit-setting in toddlerhood: Socialization strategies for the development of self-regulation. Infant Ment Health J 2006:27:344-70. 